\section{Discussion}

Emotional tension is in some but not all cases the cause of hyperhidrosis, but a vicious cycle may well be set up in which the sweating produces social embarrassment and further tension. We found that the distress caused by this condition after failure of conservative measures was an important indication for operation, after which the mental health of these patients improved remarkably and rapidly.

These results emphasize the value of sympathectomy for hyperhidrosis. Resection of the second and thind thoracic sympathetic ganglia always completely relieves hyperhidrosis of the hands. It has been stated that results are not permanent, ${ }^{7}$ but from our own experience this is not so. When an operation was done specifically for axillary hyperhidrosisthat is, resection of the fourth as well as the second and third thoracic ganglia-the results were generally good, but sometimes there was a small, easily detectable area in the apex of the axilla which could readily be excised. Several factors could be responsible for this type of sweating: firstly, there are apocrine as well as eccrine glands in the axilla; secondly, the sympathetic outflow to the axilla may not always travel exclusively through the second, third, or fourth ganglion; and, thirdly, it is technically more difficult to excise the fourth ganglion than the higher ganglia through this approach. Local excision of affected skin alone is probably to be preferred. ${ }^{8}$

Gustatory sweating can be a troublesome complication and is well documented. ${ }^{9}$ Fortunately the one case of this in the present series responded to anticholinergic drugs. Bloor ${ }^{9}$ reported 29 cases (14\%) in a series of 205 patients who had undergone cervical sympathectomy for other conditions as well as for hyperhidrosis.

That no family tendency to excessive sweating was found in any of these patients contradicts the findings of Gold. ${ }^{7} \mathrm{We}$ disagree with Gold's statement that it is impossible to denervate the axilla without producing Horner's syndrome, as we achieved this in seven patients. Horner's syndrome follows damage to the stellate ganglion, and the sympathetic outflow to the axilla passes mainly through the fourth thoracic ganglion.

\section{References}

1 Evans, C. L., British Medical Bulletin, 1957, 13, 197

2 Keele, C. A., and Neil, E., Samson Wright's Applied Physiology, 11 th edn., pp. 204, 335. London, Oxford University Press, 1965.

Kotzareff, A., Revue Medicale de la Suisse Romande, 1920, 40, 111.

Adson, A. W., Craig, W. M., and Brown, G. E., Archives of Surgery, $1935,31,794$

5 Telford, E. D., British Fournal of Surgery, 1935, 23, 448.

Hurley, H. J., and Shelley, W. B., British fournal of Dermatology, 1966, $78,127$.

Gold, S., Medical Annual, 1969, 87, 459.

8 Weaver, P. C., Postgraduate Medical fournal, 1970, 46, 422.

Bloor, K., Angiology, 1966, 17, 143.

\title{
Growing Points in Medicine
}

\section{Success and Failure in Human Virus Diseases* II-Common Viruses}

\author{
SIR CHARLES STUART-HARRIS
}

British Medical fournal, 1971, 1, 334-335

\section{Respiratory Viruses}

Turning from the rare to the commonplace brings one to the respiratory viruses. These have become familiar through their recovery largely from persons with actual illnesses. Their relation to the various respiratory syndromes ${ }^{1}$ is that none are specific for this or that clinical syndrome. Any and all of the influenza, parainfluenza, respiratory syncytial, adenoviruses, rhinoviruses, and coranaviruses may cause a sore throat, an attack of bronchitis, or a common cold. Matching viruses with syndromes has shown that each virus group is more likely to cause one than all of the other respiratory syndromes. ${ }^{2}$ Thus adenoviruses are more likely to cause a febrile sore throat than a common cold or an attack of influenza.

Influenza virus $\mathbf{B}$, but not usually $\mathbf{A}$, may cause either a febrile cold or a general "flu-like" illness, and respiratory syncytial virus attacks first and foremost the bronchiole. Disease

*Paper based on a lecture delivered to the Cardiff Medical Society on 10 November 1970.

\section{University of Sheffield}

Sir CHARLES STUART-HARRIS, M.D., F.R.c.P., Professor of Medicine due to the latter virus is limited to a narrow age range of 2 to 18 months; yet in the newborn infection may be clinically mild. ${ }^{3}$ For this reason serum antibodies derived from the mother do not necessarily prevent infection, perhaps because being immunoglobulin $G$ they do not appear in nasal secretion. Chanock ${ }^{4}$ indeed believes that union of virus in the lung with small amounts of serum antibody triggers the bronchiolar disease whereas nasal $\operatorname{IgA}$ antibody may be protective. There is no doubt that nasal antibody is important in conferring resistance to respiratory viruses, but adverse immunological reactions, though possibly important as the basis of illness in respiratory syncytial infection, are as yet unproved with other agents.

Another major problem of the respiratory viruses is their antigenic diversity. Over 100 rhinovirus types, more than 30 adenoviruses, an unknown number of coronaviruses, four parainfluenza viruses, and a constantly changing antigenic pattern of influenza viruses $A$ and $B$ furnish a veritable immunological jungle, which precludes specific prophylactic vaccines containing all components.

\section{Enteroviruses}

The large group of over 60 Coxsackie and echoviruses includes many serologically different viruses. It has become 
clear that many of these are infrequently associated with disease, whereas other types are thus related. Identified syndromes for Coxsackie $A$ viruses include herpangina, febrile respiratory disease, and hand-foot-and-mouth disease. Coxsackie B viruses seem to cause aseptic meningitis, Bornholm disease, infantile myocarditis, and adult pericarditis, but frequently in children Coxsackie $\mathbf{A}$ and sometimes Coxsackie $B$ viruses infect the throat and alimentary tract subclinically. Echoviruses are also frequent inhabitants of the alimentary tract in children yet cause aseptic meningitis, exanthemas, and rarely more serious neurological disorders. It is strange that the viruses thus far known appear to have little relation to enteritis. Fortunately for us all, the decline of poliomyelitis has seen no obvious enhancement of the activity of echoviruses, as was at one time thought to be likely. Nevertheless, small outbreaks of echovirus disease, such as echo 6 and echo 9, occur often enough for one to be wary of the future.

The practitioner who is anxious to know the cause of the minor fevers which occur in the summer season may well be faced by the fact that, particularly in children, enteroviruses can be recovered in the laboratory from the faeces without reference to the clinical condition. Serological confirmation of the infecting agent is not really applicable in this large diverse group of viruses. Isolation from actual lesions or from the central nervous system may sometimes confirm the role of the virus as the cause of the illness. For instance, echo 9 virus may be found in the C.S.F. in cases of meningitis in addition to its presence in the throat and faeces. On the whole, however, the virus laboratory is of greater help to public health workers than it is to the diagnostician in the case of enterovirus infections.

\section{Infectious Mononucleosis}

Glandular fever is a familiar clinical syndrome, and the clinician sees some patients who develop a positive Paul-Bunnell test and others without this diagnostic aid. Among the latter, the seronegative group, two groups of agents have become recognized as causative organisms. The first, Toxoplasma gon$d i i$, is probably uncommon as an acquired infection. The second, seen after cardiac operations and use of an extracorporeal circulation, seems to be an acquired infection by cytomegalovirus. ${ }^{56}$ This disease is clinically similar to glandular fever, with rash, hepatomegaly, lymphadenopathy, and atypical lymphocytes in the circulation. Cytomegalovirus, which belongs to the herpes group, is more familiar as a congenital infection causing inclusion disease of infants, but it also causes mental retardation, pneumonia, and hepatitis in neonates. $^{7}$ It is a chronic parasite in patients on immunosuppressive therapy.

Glandular fever has again been prominent recently because of the link which has been forged between it and a virus first recovered in lymphoblasts serially cultivated from African Burkitt tumours. ${ }^{8}$ This virus, known after its discoverers Epstein and Barr as E.B. virus, is also a herpes-like agent and one which is very strongly cell-associated, as are also the viruses of varicella and zoster. Henle et al. ${ }^{9}$ first showed that patients with mononucleosis develop antibodies to E.B. virus as the disease progresses. Virus-like particles have also been found in lymphocytes cultured from patients with the disease. Though E.B. antibodies occur chiefly when the Paul-Bunnell reaction is positive the latter is not essential, and in any case E.B. antibodies long outlast the heterophile ones. Prospective serological studies in students at Yale strongly suggest that glandular fever develops only in those who have no E.B. antibodies at entry to the University. ${ }^{10}$ There is, however, still no proof that E.B. virus is not simply a passenger in glandular fever, as it probably is in Burkitt tumour lymphoblasts. If it is only a passenger then it bears a remarkable similarity to the truly causative agent of infectious mononucleosis.

\section{Hepatitis}

The two disorders formerly thought to be distinct-infectious hepatitis and homologous serum jaundice-share one character in common: they have successfully defeated all attempts to cultivate their causative agents. True there have been several near-misses, but the human volunteer has so far proved to be the only susceptible animal. Interest in hepatitis has been revived in the past two years by the discovery of the Australia ( $\mathrm{Au}$ ) antigen. This antigen was first found in the serum by immunodiffusion tests with an antiserum from an Australian aboriginal and also sera from persons who had undergone multiple blood transfusions. ${ }^{11}$ The antigen is chiefly found in the serum during the acute phase of viral serum hepatitis and has also been shown therein by complement fixation and by electronmicroscopy. The astounding fact is that there is so much circulating antigen in the serum in the acute phase of the illness that a ready demonstration of the characteristic spheres and tubules by direct electronmicroscopy is possible. ${ }^{12}$ Though some workers have also found the $\mathrm{Au}$ antigen in the serum during the acute phase of infectious heparitis $^{13}$ others have failed to do so. ${ }^{14}{ }^{15}$ The distinction between patients with ordinary infectious hepatitis and those with serum hepatitis is, of course, difficult to make clinically, the different incubation period being one of the few differential characteristics.

Much argument has occurred over the precise nature of the antigen itself. Almeida and Waterson ${ }^{16}$ produced evidence that the spheres and tubules are sometimes present as aggregates, suggesting that they represented antigen-antibody complexes. Proof that the antigen is related to disease of the liver cell has come from immunofluorescence studies of liver biopsy specimens. ${ }^{17}$ Dane et al. ${ }^{18}$ have recently found another type of particle in electronmicroscopical preparations of serum containing the $\mathrm{Au}$ antigen. These particles, which are larger than the others, have a double contour more in keeping with the appearance of virus particles than the smaller spheres. Meanwhile an immediate consequence of the discovery of the Au antigen has been the ability to screen blood for evidence of carriage of the virus of serum hepatitis. It is not too much to hope that by using only Au-negative blood for transfusing patients receiving dialysis or with renal transplants one may prevent their acquisition of the virus and the dangerous state of high infectivity for their attendants in dialysis units. The relationship of the antigen to chronic liver disease is still far from clear.

\section{[Part III of this article will be published next week.]}

\section{References}

1 Stuart-Harris, C. H., Influenza and Other Virus Infections of the Respiratory Tract, 2nd edn. London, Arnold, 1965.

M.R.C. Working Party on Acute Respiratory Virus Infections, British Medical fournal, 1965, 2, 319 .

3 Neligan, Gournal, $1965,2,319$. Steiner, Medical fournal, 1970, 3, 146.

4 Chanock, R. M., Science, 1970, 169, 248.

Engle, M. A., Ehlers, K. H., and Ito, T., Advances in Pediatrics, 1964,

Embil, J. A., Folkins, D. Lancet, 1968, 2, 1151 .

Stern, H., British Medical fournal, 1968, 1, 665.

8 Epstein, M. A., Achong, B. G., and Barr, Y. M., Lancet, 1964, 1, 702. Henle, G., Henle, W., and Diehl, V., Proceedings of the National Academy of Sciences, 1968, 59, 94.

Niederman, J. C., Evans, A. S., Subrahmanvan, L., and McCollum, R. W., New England fournal of Medicine, 1970, 282, 361 .

1 Blumberg, B. S., Alter, H. J., and Visnich, S., Fournal of the American Medical Association, 1965, 191, 541.

Almeida, J. D., Zuckerman, A. J., Taylor, P. E, and Waterson, A. Microbios, 1969, 2, 117

13 Cossart, Y, 1969, 2, 117. Medical fournal, 1969 . E., Vahr

4 Giles, J. P., McCollum, 3, 755

Gew . England Mournal, R. W., Berndtson, L. W., jun., and Krugman, S. New England Fournal of Medicine, 1969, 281, 119

15 Mathews, J. D., and Mackay, I. R., British Medical fournal, 1970, 1, 259.

16 Almeida, J. D., and Waterson, A. P., Lancet, 1969, 2, 983.

Coyne (Zavatone), V. E., et al., fournal of Experimental Medicine, 1970, $131,307$.

18 Dane, D. S., Cameron, C. H., and Briggs, M., Lancet, 1970, 1, 695. 